\title{
Ocorrência do gênero Marasmius Fr. (Tricholomataceae, Agaricales) na Reserva Biológica Walter Egler, Amazonas, Brasil $^{1}$
}

\author{
Helenires Queiroz de SOUZA², Izonete de Jesus Araújo AGUIAR ${ }^{3}$
}

\section{RESUMO}

O gênero Marasmius Fr. (Tricholomataceae, Agaricales) compreende fungos comumente conhecidos como cogumelos. São cosmopolitas, mas muito mais numerosos em corpos de frutificação e espécies nas regiōes tropicais do que em regiões temperadas ou frias. Ocorrem mais freqüentemente sobre madeira ou folhas mortas ou vivas e mais raramente entre musgos ou gramíneas no solo. O presente trabalho teve como objetivo de estudo os representantes do gênero Marasmius Fr. ocorrentes na Reserva Biológica Walter Alberto Egler, município de Rio Preto da Eva, Amazonas. As coletas foram realizadas no período de dezembro de 2000 a junho de 2001 e seguiu-se a metodologia usual para identificação de Agaricales. Foi estudado um total de nove espécies: Marasmius bellus, Marasmius haedinus var. haedinus, Marasmius cf. leoninus, Marasmius cf. mazatecus, Marasmius cf. ruber, Marasmius cf. setulosifolius, Marasmius tageticolor, Marasmius cf. variabiliceps var. variabiliceps e Marasmius sp. Os táxons Marasmius cf. mazatecus, Marasmius cf. setulosifolius e Marasmius cf. variabiliceps var. variabiliceps são citados pela primeira vez para o Brasil. Com exceção de M. tageticolor Berk, as demais espécies são citadas pela primeira vez para a Reserva Walter Egler. São apresentadas descrições morfológicas, chave para identificação dos taxa e ilustrações.

PALAVRAS-CHAVE

Cogumelos, Agaricales, Amazônia.

\section{Occurrence of the genus Marasmius Fr. (Tricholomataceae, Agaricales) in the Reserva Biologica Walter Egler, Amazonas, Brazil.}

\begin{abstract}
The genus Marasmius Fr. (Tricholomataceae, Agaricales) take in fungus commonly well-known as mushrooms. It's cosmopolitan, but much more numerous in carpophore production and number of species in the tropical regions than in the temperate and frigid zones. Most frequently on wood or leaves, dead or living, more rarely among mosses or grasses on earth. A study of the representatives of the genus Marasmius occurring in the Reserva Biológica Walter Egler, Rio Preto da Eva, in the Amazon State, was carried out. The collection was carried out from December 2000 to June 2001 and the mushrooms were identified based on usual methodology for identification of Agaricales. A total of nine species were studied: Marasmius bellus, Marasmius haedinus var. haedinus, Marasmius $c f$. leoninus, Marasmius $c f$. mazatecus, Marasmius $c f$. ruber, Marasmius $c f$. setulosifolius, Marasmius tageticolor, Marasmius $c f$. variabiliceps var. variabiliceps and Marasmius sp. The taxa Marasmius $c f$. mazatecus, Marasmius $c f$. setulosifolius and Marasmius $c f$. variabiliceps var. variabiliceps are here cited for the first time from Brazil. Except of $\mathrm{M}$. tageticolor Berk, all species are cited for the first time as occurring in Reserva Walter Egler. Morphological descriptions, identification-key of the taxa and illustrations are supplied.
\end{abstract}

\section{KEY-WORDS}

Mushrooms, Agaricales, Amazonia.

${ }^{1}$ Parte da Dissertação de Mestrado da primeira autora.

${ }^{2}$ Mestrado em Botânica pelo Instituto Nacional de Pesquisas da Amazônia - INPA, e-mail: helenires@yahoo.com.br

${ }^{3}$ Coordenação de Pesquisas em Botânica CPBO/INPA, e-mail: iaguiar@inpa.gov.br. 


\section{INTRODUÇÃO}

Os fungos do gênero Marasmius Fr. pertencem à família Tricholomataceae, ordem Agaricales. O gênero possui, aproximadamente, 309 espécies, sendo a maioria em regiōes tropicais (Singer, 1986). Para o Brasil, Putzke (1994) relaciona 150 espécies do gênero Marasmius, entretanto, 40 destas são de posição incerta. É importante destacar o trabalho de Singer (1976), uma monografia bastante completa da tribo Marasmieae no neotrópico, na qual o gênero Marasmius foi representado por descrições morfológicas de 288 espécies.

Segundo Singer (1986), as principais características destes fungos são: basidioma geralmente pequeno, membranáceo, hábito colibióide ou pleurotóide. Himenóforo lamelar, raramente liso ou venoso por um longo tempo, mas eventualmente tornando-se lamelar, lamelas às vezes intervenosas ou anastomosadas. Estipe central, fino, longo, preto ou colorido. Rizomorfas negras geralmente presentes. Esporada branca. Basidiosporos lisos, inamilóides, hialinos sob o microscópio. Himênio: basídios geralmente com quatro basidiosporos. Cistídios raramente presentes. Trama himenoforal homômera, irregular. Camada cortical himeniforme ou consistindo de equinídios, ou de elementos hifais noduloso-diverticulados. Trama do píleo monomítica, pseudoamilóide ou inamilóide, sem camadas gelatinosas, fíbulas presentes ou mais raramente ausentes, se ausentes - camada cortical com equinídios. Se há um micélio basal, a camada cortical é sempre himeniforme.

Ocorrem mais freqüentemente sobre a madeira ou folhas mortas ou vivas, mais raramente entre musgos ou gramíneas no solo. Algumas espécies formam micorriza endotrófica, outras são sapróbias ou parasitas. São cosmopolitas, mas muito mais numerosos e possuem mais espécies nas regiōes tropicais do que em regiōes temperadas ou frias. Alguns representantes têm importância econômica, causando doenças em culturas tropicais tais como chá, cana-de-açúcar, café, Hevea. Outras espécies são comestíveis e comercializadas em feiras e mercados. Algumas aves usam as rizomorfas de certas espécies para construção de seus ninhos (Singer, 1986).

Além disso, estes fungos podem apresentar potencial biotecnológico, como $M$. quercophilus Pouzar, um fungo da podridão branca que coloniza e degrada liteira produzida por Quercus ilex L.. A espécie M. quercophilus é capaz de produzir vários tipos de lacase, grupo de enzimas utilizado em processos industriais como, branqueamento da polpa de papel e purificação de resíduos aromáticos em efluentes (Tagger et al., 1998; Klonowska et al., 2001). Desta forma, este trabalho teve como objetivo realizar um estudo dos fungos do gênero Marasmius Fr. ocorrentes na Reserva Walter Egler.

\section{MATERIAL E MÉTODOS}

Os fungos foram coletados na Reserva Biológica Walter
Alberto Egler, situada à margem esquerda da Estrada AM - 010, Km 64, a qual abrange uma área de, aproximadamente, 709 ha, Latitude $02^{\circ} 43^{\prime} \mathrm{S}$ e Longitude $59^{\circ} 47^{\prime} \mathrm{W}$, município de Rio Preto da Eva, Amazonas, Brasil.

O clima é tropical úmido com altas precipitações durante quase todo o ano, sendo que o período de estudo foi caracterizado por duas estações secas nos meses de dezembro e junho, altas precipitações nos meses de janeiro a maio (179,4-340,2 mm), temperatura $\left(25,8-27,5^{\circ} \mathrm{C}\right)$ e umidade relativa do ar (91-93\%) constantes (Souza, 2002).

A Reserva Egler é constituída de floresta de terra firme, com solo argiloso, caracterizado como Latossolo vermelho amarelo. A vegetação está sobre um relevo acidentado, ocorrendo em alguns locais, áreas de baixio, vertente e platô, além de igarapés (Souza et al., 2003).

O período de coleta correspondeu aos meses de dezembro de 2000 a junho de 2001. Os basidiomas foram coletados ao longo de trilhas na floresta abrangendo áreas de platô, vertente e baixio, e colocados em sacos individuais de papel ou recipientes plásticos, anotando-se as características do habitat (Sousa, 1980).

Para a identificação taxonômica, procedeu-se a metodologia usual para Agaricales, observando-se características macroscópicas dos basidiomas ainda frescos e das microestruturas (basídios, basidiosporos, cistídios e hifas) após a desidratação do material em estufa com temperatura entre 50-60 ${ }^{\circ} \mathrm{C}$. (Martin, 1934; Kotlaba \& Pouzar, 1964; Singer, 1986). Medidas do píleo e estipe foram realizadas com régua milimetrada e as tonalidades de cores foram identificadas por meio da carta de cores de Locquin (1975). A observação das microestruturas foi realizada em microscópio binocular Zeiss. As medidas foram obtidas com o auxílio de uma ocular micrométrica P15x Kyowa, acoplada ao microscópio e objetiva de 100x. Para cada microestrutura foram medidas 10 amostras, obtendo-se os valores extremos. Os basidiomas foram fotografados e as microestruturas foram desenhadas com auxílio de uma câmara clara, acoplada ao microscópio trinocular Zeiss e transferidas para papel vegetal com caneta nanquim.

A identificação taxonômica foi baseada em Dennis (1970), Singer (1976 e 1986), Pegler (1977) e literatura complementar. A terminologia micológica seguiu os trabalhos de Snell \& Dick (1957) e Fidalgo \& Fidalgo (1967). A confecção da chave, para a identificação dos táxons, foi realizada por meio dos caracteres macro e microscópicos dos basidiomas. Todo o material coletado foi depositado no Herbário do INPA, Manaus-AM.

\section{RESULTADOS E DISCUSSÃO}

São apresentadas as características morfológicas de nove espécies do gênero Marasmius Fr. coletadas na Reserva Biológica Walter Alberto Egler, Rio Preto da Eva, Amazonas. Apresentamse ainda, chave de identificação das espécies, descrições, habitat e 
distribuição, espécimes examinados, comentários e ilustrações.

Chave para identificação das espécies de Marasmius estudadas

1. Lamelas colariadas 2

2. Elementos epicuticulares constituídos por equinídios do tipo Siccus.. M. cf. variabiliceps var. variabiliceps

2'. Camada epicuticular formada por equinídios do tipo Rotalis Marasmiussp.

1'. Lamelas não colariadas 3

3. Cistídios presentes ... 4

3'. Cistídios não observados M. leoninus.

4. Pleurocistídios em forma de equinídios, píleo alaranjado M. cf. setulosifolius.

4'. Pleurocistídios clavados, píleo branco.. M. haedinus var. haedinus

5. Píleo branco, pleurocistídios ausentes M. bellus

5'. Píleo colorido, pleurocistídios ausentes ... 6

6. Lamélulas presentes, píleo laranja-amarronzado .... M. cf. ruber 6'. Lamélulas ausentes, píleo de outra cor...... . .7

7. Basidiosporos de $12 \mathrm{~mm}$ . .8

8. Estipe filiforme, píleo marrom................... cf. mazatecus

8'. Estipe cilíndrico, píleo marrom-avermelhado.... M. cf. leoninus

7’. Basidiosporos de 15 a $23 \mathrm{~mm}$, píleo vermelho-escarlate M. tageticolor

Marasmius cf. variabiliceps Singer var. variabiliceps, Sydowia 18: 344. 1965. Tipo. BOLIVIA. La Paz: Nor-Yungas, Carmem pampa, 26 Fev. 1956, Singer B 1531 (Holótipo, LIL) (Figuras 1 e $10 \mathrm{C})$.

Píleo coriáceo, 17 mm de diâmetro, campanulado, plissado, com o centro depressado, superfície áspera, bordas lisas, coloração vinho-azulado (L2b vinaceus). Lamelas semelhantes a colar, estreitas, poucas, lamélulas ausentes, consistência coriácea, bordas onduladas, coloração bege (FGh aurantiacus). Estipe $155 \mathrm{~mm}$ de comprimento, central, filiforme, consistência fibrosa, lustroso, cor preta (B1a phaeotus). Basidiosporos 5,55-8,88 x 2,22-3,33 $\mathrm{m}$, fusiforme-elíptico, lisos, hialinos, inamilóides, cianófilos. Himênio: Basídios 16,65-22,2 x 4,44-5,55 mm, claviformes, amarelados, pseudoamilóides, cianófilos. Queilocistídios, equinídios tipo Siccus, amarelados. Trama himenoforal irregular; cianófila, pseudoamilóide, hialina em hidróxido de potássio. Camada cortical do píleo himeniforme, equinídios tipo Siccus 12,2-18,33 mm, castanhos em hidróxido de potássio.

Habitat e distribuição geográfica: Floresta de terra firme primária, vertente, solo argilo-arenoso. Sobre folha na serapilheira. Amazonas, Brasil. Bolívia (Singer, 1976).

Material examinado: BRASIL: Amazonas, Rio Preto da Eva, Reserva Biológica Walter Alberto Egler, col. H.Q. Souza \& I.J.A. Aguiar 54, 30 Abr 2001 (INPA 210.036).
Comentários: O fungo coletado é semelhante à descrição feita por Singer (1976), entretanto, o estipe do material estudado é bem maior $(155 \mathrm{~mm})$, quando comparado à descriçãao original (58-100 mm).

\section{Marasmius sp. (Figura 2)}

Píleo membranáceo, $7 \mathrm{~mm}$ de diâmetro, campanulado, plissado, papila central um pouco mais escura, superfície lisa, bordas onduladas, bege-claro (F7h aurantiacus). Lamelas em colar, largas, distantes, numerosas, consistência membranácea, bordas lisas, concolor ao píleo. Estipe $20 \mathrm{~mm}$ de comprimento, central, filiforme, fibroso, base abrupta, superfície estriada, preto (B1a phaeotus). Basidiosporos 4,44-11,1 x 2,22-3,33 mm, obovados, lisos, hialinos, inamilóides, cianófilos. Himênio: Basídios 16,65-25 × 3,33 mm, claviformes, hialinos, inamilóides, cianófilos. Queilocistídios, equinídios tipo Rotalis. Trama himenoforal irregular, cianófila, ausência de reaçôes amilóides, hialina em hidróxido de potássio. Camada cortical do píleo himeniforme, equinídios tipo Rotalis 20,5-37,7 mm.

Habitat e distribuição geográfica: Floresta de terra firme primária, platô, solo argiloso, baixio solo arenoso. Sobre folha caída na serapilheira. Amazonas, Brasil.

Material examinado: BRASIL: Amazonas, Rio Preto da Eva, Reserva Biológica Walter Alberto Egler, col. H.Q. Souza \& I.J.A. Aguiar 6, 13 Dez 2000 (INPA 210.003); col. H.Q. Souza 23, 30 Jan 2001 (INPA 210.015); col. H.Q. Souza \& I.J.A. Aguiar 64, 30 Abr 2001 (INPA 210.041).

Comentários: A espécie estudada distingue-se principalmente pelo píleo de $7 \mathrm{~mm}$, campanulado, plissado, bege-claro, papila central um pouco mais escura. Estipe $20 \mathrm{~mm}$ preto. Basidiosporos 4,44-11,1 x 2,22-3,33 mm, obovados.

Marasmius cf. setulosifolius Singer ex Singer, Sydowia 18:343.
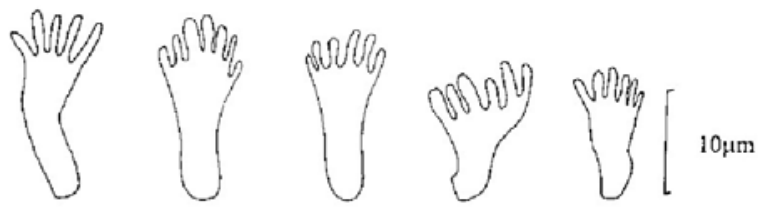

A
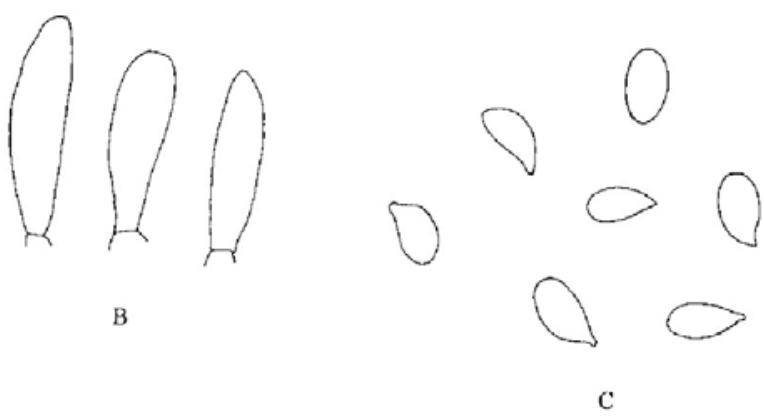

Figura 1 - Marasmius cf. variabiliceps Singer var. variabiliceps A. Elementos da camada cortical, equinídios tipo Siccus; B. Basidíolos; C, Basidiosporos. 

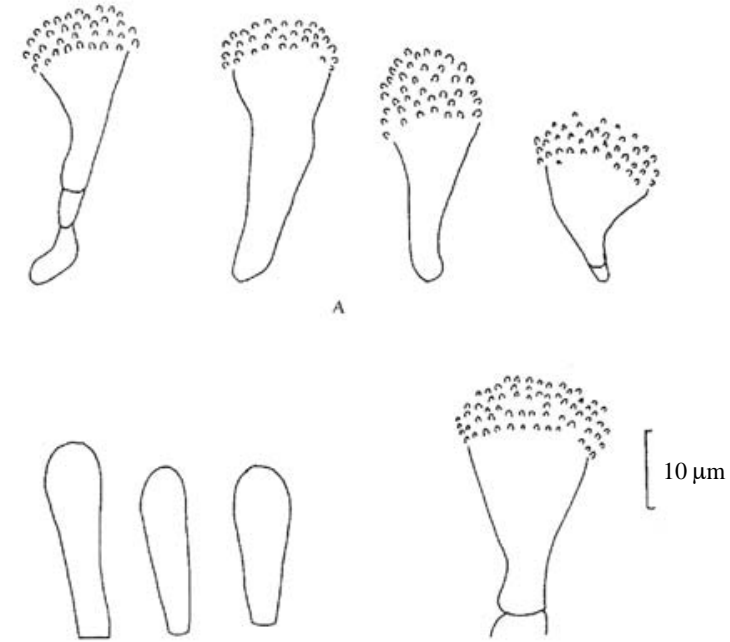

B

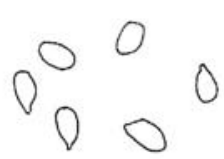

Comentários: A espécie examinada coincide com a descrição dada por Singer (1976), entretanto difere pelo comprimento do estipe que é menor $(13 \mathrm{~mm})$, do que o comprimento descrito por esse autor $(28-40 \mathrm{~mm})$.

Marasmius haedinus Berkeley var. haedinus, Hook. Jour. Bot. 8:135. 1856. Tipo. BRASIL. Amazonas, "Panuré" (= Ipanuré. Agora São Jerônimo), Spruce 31 (Holótipo, K). (Figuras 4, 11C e 11E).

Píleo membranáceo, 11-37 mm de diâmetro, convexocampanulado, superfície velutínea, bordas lisas, coloração branca (H8h albus). Lamelas livres, estreitas, distantes, lamélulas ausentes, consistência membranácea, bordas onduladas, concolor ao píleo. Estipe 5-23 mm de comprimento, central, filiforme, consistência fibrosa, lustrosa, coloração vinho (B1c phaeotus) com ápice branco, micélio na base. Odor de tangerina. Basidiosporos 4,4415,54 x 2,22-3,88 mm, elípticos, lisos, hialinos, inamilóides, cianófilos. Himênio: Basídios 16,65-33,3 x 2,22-7,77 mm, claviformes, 2 esterigmas, amarelo-claros, inamilóides, cianófilos. Pleurocistídios 24,42 × 2,22 mm, clavados. Queilocistídios, equinídios tipo Siccus. Trama himenoforal irregular; cianófila, pseudoamilóide, amarelo-acinzentado em hidróxido de potássio. Hifas 3,33-6,66 mm de diâmetro. Camada cortical do píleo himeniforme, equinídios de 19,98-22,22 mm.

Habitat e distribuição geográfica: Floresta de terra firme

1965. Tipo. BOLIVIA. Beni: vaca Diez, Guayaramerim, 7 Mar 1956, Singer B 1649 (Holótipo, LIL). (Figuras 3 e 11D).

Píleo membranáceo, $20 \mathrm{~mm}$ de diâmetro, campanulado, superfície velutínea, bordas lisas, alaranjado (B4g russus). Lamelas adnatas, estreitas, distantes, membranáceas, bordas lisas, lamélulas ausentes, concolor ao píleo. Estipe $13 \mathrm{~mm}$ de comprimento, central, cilíndrico, consistência membranácea, coloração laranjaesverdeado (C6g aurantiacus), presença de micélio basal. Basidiosporos 7,77-8,88 x 3,33 mm, piriformes a fusiformeelípticos, lisos, hialinos, inamilóides, cianófilos. Himênio: Basídios não observados. Basidíolos 16,65-33,3 x 4,44-5,55 mm, claviformes, hialinos, inamilóides. Pleurocistídios e queilocistídios 24,42-33,3 x 5,55-11,1 mm, semelhantes aos equinídios, diferindo destes por serem mais alongados. Equinídios tipo Siccus presente entre os queilocistídios. Trama himenoforal irregular, acianófila, pseudoamilóide, hialina em hidróxido de potássio. Hifas 2,22-5,55 mm de diâmetro. Camada cortical do píleo himeniforme, equinídios tipo Siccus 16,66-22,22 mm, castanhos em hidróxido de potássio.

Habitat e distribuição geográfica: Floresta de terra firme primária, platô, solo argiloso. Sobre folha de palmeira. Amazonas. Panamá e Bolívia (Singer, 1976), Colômbia (Pulido, 1983). Citada pela primeira vez para o Brasil.

Material examinado: BRASIL: Amazonas, Rio Preto da Eva, Reserva Biológica Walter Alberto Egler, col. H.Q. Souza 90, 27 Jun 2001(INPA 210.056).

primária, platô, solo argiloso, vertente, solo argilo-arenoso. Sobre folhas secas ou galhos secos. Singer (1976) citou esta espécie

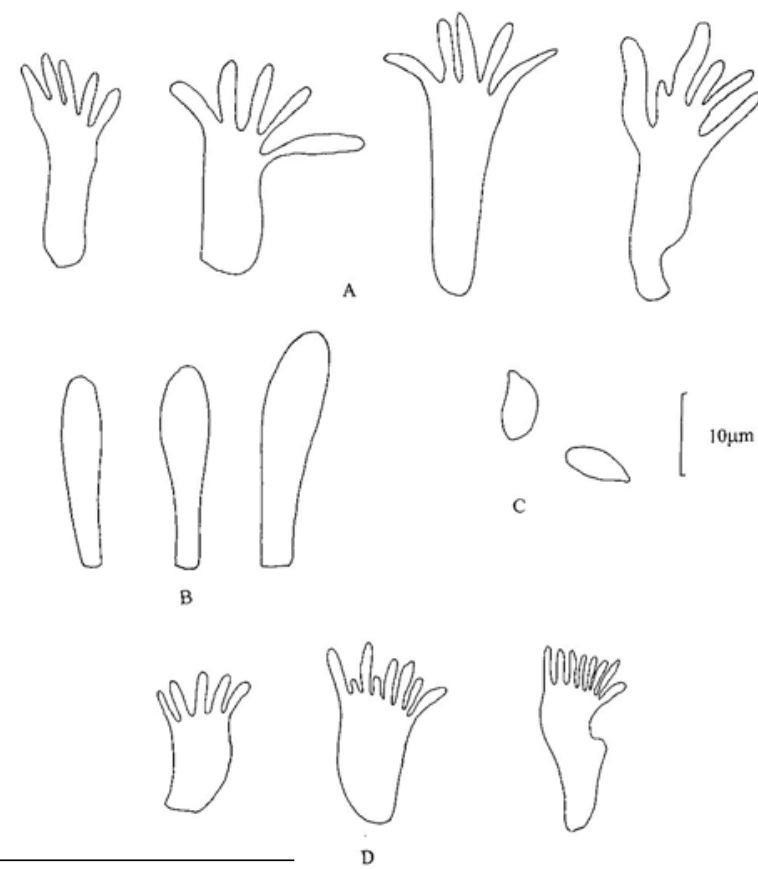

Figura 3 - Marasmius cf. setulosifolius Singer ex Singer: A. Cistídios; B. Basidíolos; C. Basidiosporos; D. Elementos da camada cortical, equinídios tipo Siccus. 
anteriormente para o Brasil (Amazonas e Pará), Trinidad, Colômbia, e Bolívia.

Material examinado: BRASIL: Amazonas, Rio Preto da Eva, Reserva Biológica Walter Alberto Egler, col. H.Q. Souza 11, 30 Jan 2001 (INPA210.006); col. H.Q. Souza 25, 30 Jan 2001 (INPA 210.017); col. H.Q. Souza \& I.J.A. Aguiar 53, $30 \mathrm{Abr}$ 2001 (INPA 210.035); col. H.Q. Souza 79, 27 Jun 2001 (INPA 210.049); col. H.Q. Souza 93, 27 Jun 2001 (INPA 210.060); col. H.Q. Souza 96, 27 Jun 2001 (INPA 210.062);

Comentários: A espécie estudada é caracterizada no campo pela coloração branca do píleo, lamelas estreitas e distantes, estipe vinho lustroso e forte odor de tangerina. O píleo dos espécimes estudados é mais largo (11-37 mm) que o da descrição de Singer (1976), que foi de 10-23 mm. A espécie já havia sido citada para o Brasil por Singer (1976), coletada nos Estados do Pará e Amazonas.

Marasmius bellus Berkeley, Hook. Jour. Bot. 8:139. 1856. Tipo. BRASIL. Amazonas: "Panuré", Spruce (Holótipo, K). (Figuras 5 e 11A).

Píleo membranáceo, 14-26 mm de diâmetro, convexo, coloração branca (H8h albus), superfície lisa, bordas lisas. Lamelas adnatas, fortemente intervenosas, concolor ao píleo, consistência membranácea, bordas onduladas. Estipe $50 \mathrm{~mm}$ de comprimento, central, filiforme, fibroso, coloração vinho (B1b phaeotus). Micélio marrom na base. Odor forte de tangerina.

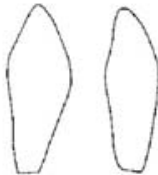

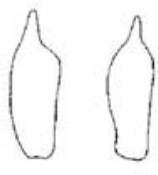
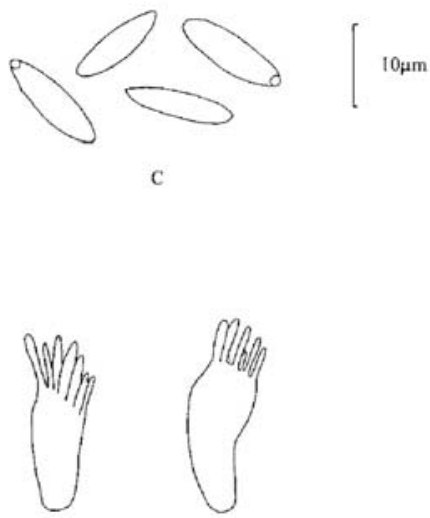

D

Figura 4 - Marasmius haedinus Berk. var. haedinus: A. Pleurocistídios; B. Basidíolos; C. Basidiosporos; D. elementos da camada cortical.
Basidiosporos 11,1 x 3,33 mm, fusiforme-elípticos a naviculados, lisos, hialinos, inamilóides, cianófilos. Himênio: Basídios não observados. Basidíolos 18,33-27,75 x 3,33-5,55 mm, fusiformes, hialinos, inamilóides. Queilocistídios, equinídios, inamilóides. Trama himenoforal irregular, acianófila, pseudoamilóide, hialina em hidróxido de potássio. Hifas 5,55 $\mathrm{mm}$ de diâmetro. Camada cortical do píleo himeniforme, equinídios tipo Siccus 9,99-16,66 mm, pseudoamilóides, castanhos em hidróxido de potássio.

Hábitat e distribuição geográfica: Floresta de terra firme primária, platô, solo argiloso, vertente, solo argilo-arenoso. Sobre galho caído na serapilheira. A espécie já havia sido citada para o Brasil (Amazonas e Pernambuco) e Bolívia por Singer (1976) e para a Colômbia (Pulido, 1983).

Material examinado: BRASIL: Amazonas, Rio Preto da Eva, Reserva Biológica Walter Alberto Egler, col. H.Q. Souza 68, 27 Jun 2001 (INPA 210.044); col. H.Q. Souza 76, 27 Jun 2001(INPA 210.048).

Comentários: A espécie estudada é caracterizada, sobretudo por apresentar píleo membranáceo, 14-26 mm de diâmetro, convexo, branco. Lamelas intervenosas, concolor ao píleo. Estipe de $50 \mathrm{~mm}$ de comprimento, vinho. Odor forte de tangerina. Basidiosporos de 11,1 x 3,33 mm, fusiforme-elípticos a naviculados. Pela descrição de Singer (1976), a presença das lamelas intervenosas é a principal característica que distingue $\mathrm{M}$. bellus das espécies $\mathrm{M}$. haediniformis e M. haedinus.

Marasmius cf. ruber Singer, Sydowia 18:342. 1965. Tipo. BOLÍVIA. Beni: Vaca Diez, Guayaramerin, 7 Mar 1956, Singer B 1638 (Holótipo, LIL). (Figuras 6 e 11F).
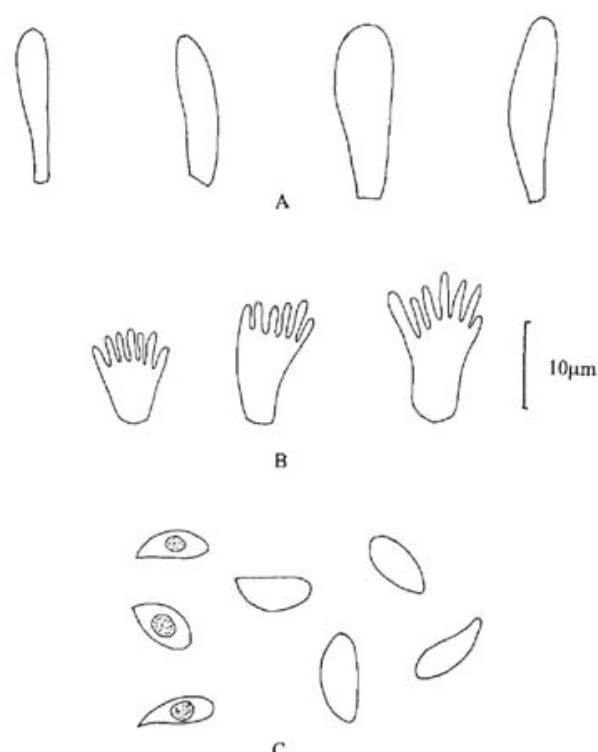

Figura 5 - Marasmius bellus Berkeley: A. Basidíolos; B. Elementos da camada cortical; C. Basidiosporos. 
Píleo membranáceo, 6-30 mm de diâmetro, convexo a planoconvexo, plissado, superfície velutínea, bordas onduladas, coloração laranja-amarronzado (E3f carbuncutis). Lamelas subdecurrentes, estreitas, numerosas, lamélulas presentes na margem do píleo ou não, consistência membranácea, bordas onduladas, coloração variando de branca (H8h albus) à cor do píleo. Estipe 4-20 mm de comprimento, central, filiforme, recurvado, consistência fibrosa, marrom (J1e phaeotus) a laranjaescuro (B3g rubeus), micélio branco-brilhante, cotonoso na base. Escamas concolor ao píleo. Basidiosporos 5,55-12,21 x 2,224,44 mm, fusiforme-elípticos, lisos, hialinos, inamilóides, cianófilos. Himênio: Basídios 16,65-27,75 x 5,55-6,66 mm, claviformes, 2-4 esterigmas, hialinos, inamilóides, cianófilos. Queilocistídios, equinídios, castanhos em hidróxido de potássio. Trama himenoforal irregular; cianófila, pseudoamilóide, amarelada em hidróxido de potássio. Hifas com 4,44-5,55 mm de diâmetro. Camada cortical do píleo himeniforme, equinídios, castanhos em hidróxido de potássio.

Habitat e distribuição geográfica: Floresta de terra firme primária, platô, solo argiloso. Sobre galhos secos ou sobre folha seca de palmeira. Amazonas, Brasil. A espécie havia sido citada anteriormente para Trinidad e Bolívia (Singer, 1976).

Material examinado: BRASIL: Amazonas, Rio Preto da Eva, Reserva Biológica Walter Alberto Egler, col. H.Q. Souza 12, 30 Jan 2001 (INPA 210.007); col. H.Q. Souza 13, 30 Jan 2001 (INPA 210.008); col. H.Q. Souza 65, 27 Jun 2001 (INPA 210.042); col. H.Q. Souza 70, 27 Jun 2001 (INPA 210.046); col. H.Q. Souza 82, 27 Jun 2001 (INPA 210.051).

Comentários: A espécie estudada está mais próxima de $M$. ruber Sing. pela coloração do basidioma, pelo diâmetro do píleo e tamanho dos basidiosporos. Entretanto, a variação do comprimento do estipe da espécie estudada é menor que a descrição dada por Singer (1976), 15-48 mm. Além disso, o aspecto recurvado do estipe também a diferencia.

Marasmius cf. mazatecus Singer, Flora Neotropica, Monograph 17: 168, 1976. Tipo. MÉXICO. Oaxaca: San André Hidalgo, Sierra Mazateca, 8 Jul 1969, Singer M 8368 (Holótipo, F). (Figuras 7 e 10B).

Píleo membranáceo, 12-17 mm de diâmetro, campanulado, superfície velutínea, bordas lisas, coloração marrom (A2d russus). Lamelas decurrentes, largas, poucas, lamélulas ausentes, consistência membranácea, bordas lisas, beges (D5h aurantiacus). Estipe 19-21 mm de comprimento, central, filiforme, consistência fibrosa, cor marrom (J1d venetus), micélio branco na base. Odor adocicado. Basidiosporos 12,22-13,33 x 3,33 mm, fusiformeelípticos, lisos, hialinos, inamilóides, cianófilos. Himênio: Basídios 16,65-27,77 x 4,44-5,55m, claviformes, 2-4 esterigmas, hialinos, inamilóides, cianófilos. Queilocistídios, equinídios tipo Siccus, castanhos em hidróxido de potássio. Trama himenoforal irregular; cianófila, pseudoamilóide, hialina em hidróxido de potássio. Hifas 3,33-4,44 mm de diâmetro. Camada cortical do píleo himeniforme, equinídios tipo Siccus 14,44-22,22 mm, castanhos em hidróxido de potássio.

Habitat e distribuição geográfica: Floresta de terra firme primária, platô, solo argiloso. Sobre raiz na serapilheira. Amazonas, Brasil. Singer (1976) cita esta espécie para o México.

Material examinado: BRASIL: Amazonas, Rio Preto da Eva, Reserva Biológica Walter Alberto Egler, col. H.Q. Souza \& I.J.A. Aguiar 40, 30 Abr 2001 (INPA 210.025).

Comentários: As características do fungo estudado são semelhantes com a espécie descrita por Singer (1976), entretanto os basidiosporos descritos por este autor são maiores (17-21 x 3,5-4,5 mm).

Marasmius cf. leoninus Berkeley, Hook. Jour. Bot. 8:135.1856. Tipo. BRASIL. Amazonas: 'Panuré", Mar 1853, Spruce 112 (Holótipo, K). (Figuras 8 e 10A).

Píleo membranáceo, $25 \mathrm{~mm}$ de diâmetro, campanulado, plissado, superfície velutínea, bordas lisas, coloração marromavermelhado (C2d phaeotus). Lamelas sinuadas, estreitas, numerosas, lamélulas ausentes, consistência membranácea, bordas irregulares, cor cinza (F5g cinereus). Estipe $40 \mathrm{~mm}$ de comprimento, central, cilíndrico, levemente achatado, fibroso, lustroso, cor marrom-escuro (D1c vinaceus). Basidiosporos 12,22 x 3,88 mm, cilíndricos, lisos, hialinos, inamilóides. Himênio: Basídios 22,22 x 7,77-10,55 mm, cilindro-clavados, 2-4 esterigmas, hialinos, inamilóides, cianófilos. Cistídios não observados. Trama himenoforal irregular, cianófila, pseudoamilóide, hialina em hidróxido de potássio. Hifas 3,336,66 mm de diâmetro. Camada cortical do píleo himeniforme, equinídios 8,33-10,55 $\mathrm{mm}$ castanhos.
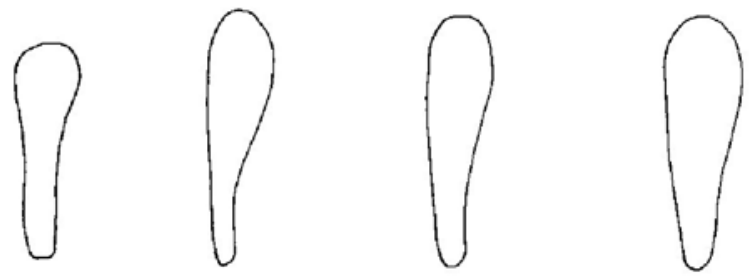

A
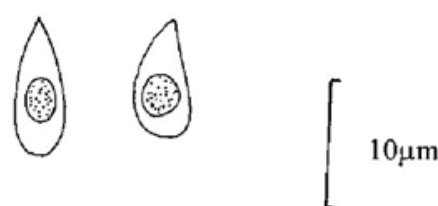

$B$

Figura 6 - Marasmius cf ruber Sing.: A. Basidíolos; B. Basidiosporos. 
Habitat e distribuição geográfica: Floresta de terra firme primária, vertente, solo argilo-arenoso. Sobre tronco morto. Espécie mencionada para o Brasil (Amazonas e Rio Grande do Sul), Estados Unidos, Venezuela, Equador, Bolívia e Argentina (Singer, 1976).

Material examinado: BRASIL: Amazonas, Rio Preto da Eva, Reserva Biológica Walter Alberto Egler, col. H.Q. Souza \& I.J.A. Aguiar 58, 30 Abr 2001 (INPA 210.039).

Comentários: As características de Marasmius leoninus var. leoninus descrita por Singer (1976) são semelhantes com a espécie estudada neste trabalho, mas a presença de rizomorfas esbranquiçadas não foi observada neste exemplar. Presença de pequenas larvas.

Marasmius tageticolor Berkeley, Hook. Jour. Bot. 8: 136. 1856. Tipo. BRASIL. Amazonas: “Panuré”, Spruce 37 (Holótipo, K). (Figuras 9 e 11B).
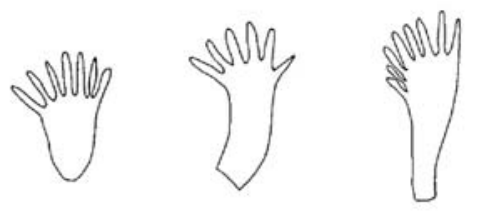

A

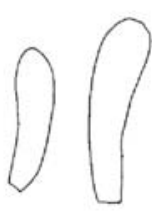

B

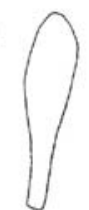

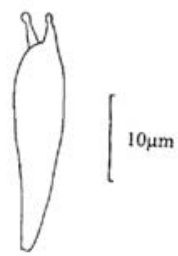

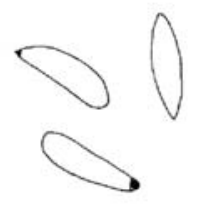

D

Figura 7 - Marasmius cf. mazatecus Singer: A. Elementos da camada cortical; B. Basidíolos; C. Basídio; D. Basidiósporos.

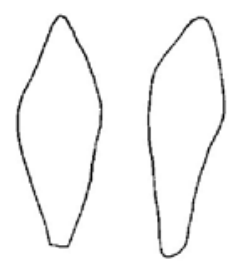

A
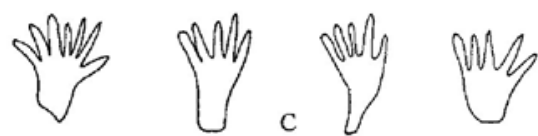

Figura 8 - Marasmius cf. leoninus Berk.: A. Basidíolos; B. Basidiosporos; C. Elementos da camada cortical.
Píleo membranáceo, 20-30 mm de diâmetro, campanulado, superfície velutínea, bordas lisas, coloração vermelho-vináceo (B1d phaeotus). Lamelas livres, estreitas, distantes, membranáceas, bordas onduladas, lamélulas ausentes, coloração bege (F8h aurantiacus). Estipe 60-90 mm de comprimento, central, filiforme, consistência fibrosa, superfície lustrosa, coloração marrom-vináceo (Ed3 vinaceus), presença de micélio basal. Basidiosporos 15,55-23,31 x 2,22-4,44 mm, fusiforme-elípticos a naviculados, lisos, hialinos, inamilóides, cianófilos. Himênio: Basídios 22,22-33,3 x 4,44-8,88 mm, claviformes, 2-4 esterigmas, hialinos, inamilódes, cianófilos; basidíolos claviformes, hialinos. Queilocistídios, equinídios hialinos. Trama himenoforal irregular, cianófila, pseudoamilóide, hialina em hidróxido de potássio. Hifas 2,22 -3,33 mm de diâmetro. Camada cortical do píleo himeniforme, equinídios tipo Siccus $11,11 \mathrm{~mm}$, castanhos em hidróxido de potássio.

Habitat e distribuição geográfica: Floresta de terra firme primária, platô, solo argiloso, baixio, solo arenoso. Ocorre sobre folha e sobre galho caído na serapilheira. A espécie é mencionada para o Brasil (Amazonas), Venezuela, México (Singer, 1976).

Material examinado: BRASIL: Amazonas, Rio Preto da Eva, Reserva Biológica Walter Alberto Egler, col. H.Q. Souza \& I.J.A. Aguiar 8, 13 Dez 2000 (INPA 210.004); col. H.Q. Souza 16, 30 Jan 2001 (INPA 210.011); col. H.Q. Souza 30, 30 Jan 2001 (INPA 210.020); col. H.Q. Souza 81, 27 Jun 2001 (INPA 210.050); col. H.Q. Souza 92, 27 Jun 2001 (INPA 210.059);
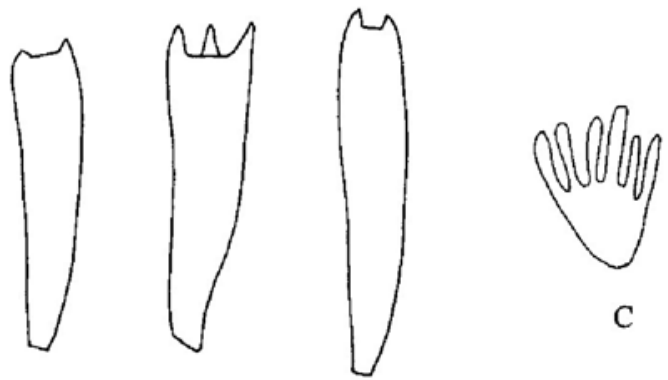

A

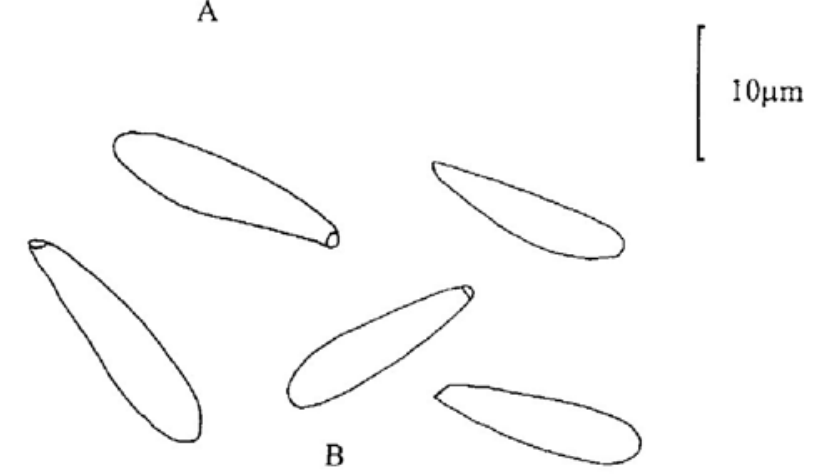

Figura 9 - Marasmius tageticolor Berk.: A. Basídios; B. Basidiosporos; C. Elemento da camada cortical, equinídio tipo Siccus. 

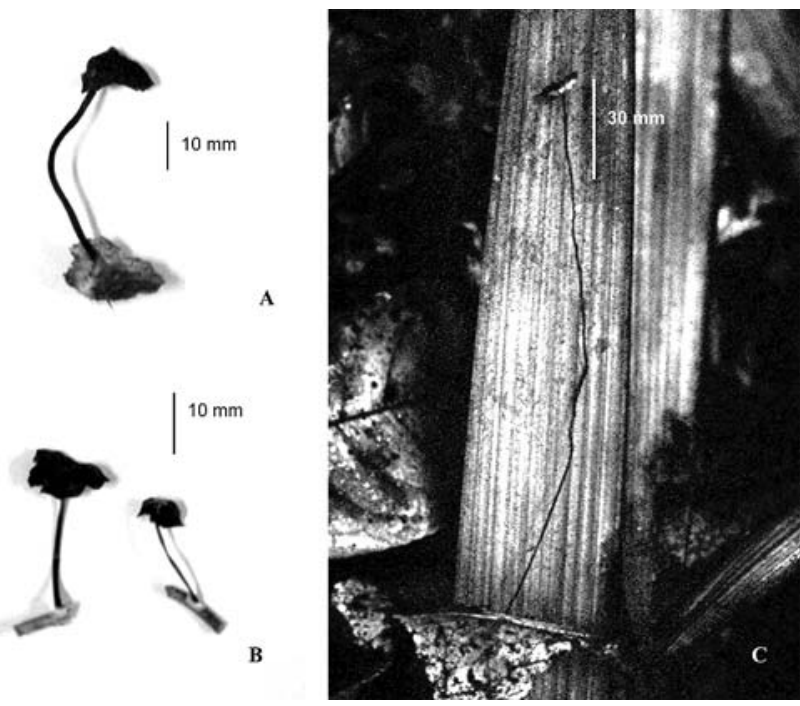

Figura 10 - Fungos do gênero Marasmius coletados na Reserva Egler: A) Marasmius leoninus, B) $M$. mazatecus, C) $M$. variabiliceps var. variabiliceps.

col. H.Q. Souza 94, 27 Jun 2001 (INPA 210.061); col. H.Q. Souza 99, 27 Jun 2001 (INPA 210.064).

Comentários: Segundo Singer (1976), esta espécie é encontrada sobre galhos e folhas caídos sobre o solo de floresta tropical, concordando com os espécimes coletados neste trabalho. A espécie já havia sido citada para o Brasil por Singer (1976) em coleta realizada no Amazonas. Moura \& Aguiar (2001) citam Marasmius tageticolor Berk. pela primeira vez para a Reserva Egler.

\section{BIBLIOGRAFIA CITADA}

Dennis, R.W.G. 1970. Fungus flora of Venezuela and adjacent countries. Vol.3. Kew Bull. Add. Ser. London, UK. 531pp.

Fidalgo, O.; Fidalgo, M.E.P.K. 1967. Dicionário Micológico. Rickia, supl.2: 1-232.

Klonowska, A.; Petit, J.L.; Tron, T. 2001. Enhancement of minor laccases production in the basidiomycete Marasmius quercophilus C30. FEMS Microbiology Letters, 200: 25-30.

Kotabla, F.; Pouzar, Z. 1964. Preliminary results of the staining of spores and other structures of Homobasidiomycetes in cotton blue and its importance for taxonomy. Feddes Report., 69(2): 131-142.

Locquin, M.V. 1975. Guide des coulers naturelles 1. De Taxia Fungorum.

Martin, G. W. 1934. Three new Heterobasidiomycetes. Mycologia, 25: 261-265.

Moura, M.C.N.; Aguiar, I.J.A. 2001. Diversidade de fungos macroscópicos na Reserva Florestal Walter Egler, Manaus, Amazonas, Brasil. In: X Jornada de Iniciação Científica do INPA, Manaus, Amazonas. Anais da X Jornada de Iniciação Científica do INPA, Manaus, Amazonas, Brasil. p. 23-25.

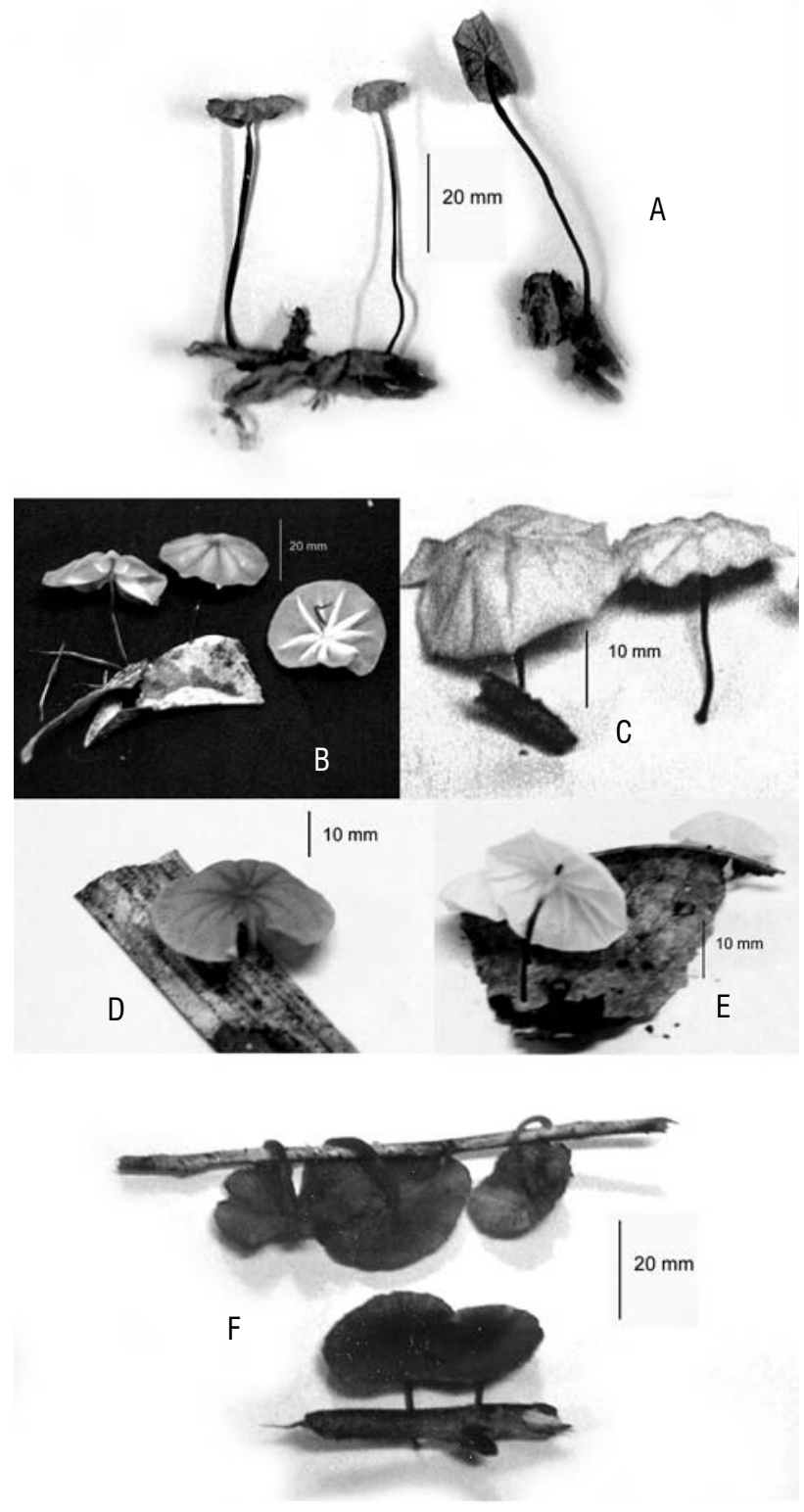

Figura 11 - Fungos do gênero Marasmius coletados na Reserva Egler: A) M. bellus, B) M. tageticolor, C) M. haedinus var. haedinus, D) M.setulosifolius, E) M. haedinus var. haedinus, F) M. ruber.

Pegler, D.N. 1977. A preliminary agarici Flora of East Africa. Kew Bulletin. Additional Series, 6: 615 pp.

Pulido, O.M.M. 1983. Estúdios em Agaricales Colombianos - los hongos de Colombia IX. Univ. Nac. de Colombia, Bogotá, Colombia. 143pp.

Putzke, J. 1994. Lista dos fungos Agaricales (Hymenomycetes, Basidiomycotina) referidos para o Brasil. Caderno de Pesquisa. Sér. Bot./Universidade de Santa Cruz do Sul, 6(2): 186.

Singer, R. 1976. Marasmieae (Basidiomycetes-Tricholomataceae). Flora Neotropica Monograph, 17: 1-347. 


\section{ACTA}

Singer, R. 1986. The Agaricales in modern taxonomy. $4^{\text {th }}$ Edition, Koeltz Scientific Books, Koenigstein, Germany. 981pp.

Snell. W.H.; Dick, E.A. 1957. A glossary of mycology. Harvard University Press, Cambridge. 170pp.

Sousa, M.A. 1980. O gênero Phellinus Otréler (Hymenomycetes) na Amazônia brasileira. Tese de Doutorado, Instituto Nacional de Pesquisas da Amazônia/Universidade do Amazonas, Manaus, Amazonas. 190pp.

Souza, H.Q. 2002. Agaricales da Reserva Biológica Walter Alberto Egler, Amazonas, Brasil. Dissertação de Mestrado, Instituto Nacional de Pesquisas da Amazônia/Universidade Federal do Amazonas, Manaus, AM. 173pp.
Souza, M.C.; Guillaumet, J.L.; Aguiar, I.J.A. 2003. Ocorrência e distribuição de teridófitas na Reserva Florestal Walter Egler, Amazônia Central, Brasil. Acta Amazonica, 33(4): 555-562.

Tagger, S.; Périssol, C.; Gil, C.; Vogt, G.; Petit, J.L. 1998. Phenoloxidases of the White-rot fungus Marasmius quercophilus isolated from an evergreen oak litter (Quercus ilex L.). Enzyme and Microbial Technology, 23: 372-379.

Recebido em 25/08/2004

Aceito em 01/12/2006 
